\title{
Alkalinizing the Intralysosomal pH Inhibits Degranulation of Human Neutrophils
}

\author{
Mark S. Klempner and Barbara Styrt, Department of Medicine, \\ Division of Experimental Medicine, Tufts University \\ School of Medicine, Boston, Massachusetts 02111
}

\begin{abstract}
A B S T R A C T Degranulation of lysosomes is one of the consequences of neutrophil activation. Regulatory mechanisms of lysosomal secretion are thought to be localized largely in the plasma membrane and cytosol, with the lysosome playing a passive role in secretion. Recent evidence indicates that the intralysosomal $\mathrm{pH}$ is highly acidic $(\mathrm{pH} \simeq 5.5)$ and is maintained by active transport of $\mathrm{H}^{+}$. We investigated whether changes in the intralysosomal $\mathrm{pH}$ altered the availability of lysosomes for exocytosis. Intralysosomal $\mathrm{pH}$ in intact neutrophils was monitored with the weakly basic fluorescent probe, 9-aminoacridine (9AA). The weak bases, methylamine, chloroquine, clindamycin, propanolol, and ammonium chloride (0.1-50 mM), caused an alkalinization of the intralysosomal $\mathrm{pH}$ as determined by reversal of quenching of 9AA fluorescence. Similarly, each of the weak bases, including ammonium chloride, methylamine, chloroquine, ethylamine, propylamine, propanolol, clindamycin, and dansylcadaverine, inhibited neutrophil degranulation in response to the calcium ionophore A23187, phorbol myristate acetate, or the chemotactic peptide, formylmethionine-leucine-phenylalanine plus cytochalasin B. These studies indicate that an acid intralysosomal $\mathrm{pH}$ is important to the neutrophil secretory response and suggest that the lysosome may play an active part in control of degranulation.
\end{abstract}

\section{INTRODUCTION}

Fusion of intracellular granules (lysosomes) with the plasma membrane is a fundamental event in cell biology related to normal endocytic and exocytic functions.

This work was was presented in part at the American Federation for Clinical Research, National Meeting, April 29May 2, 1983, Washington, DC.

Received for publication 15 June 1983 and in revised form 3 August 1983.
This process underlies such diverse phenomena as intracellular digestion, neurotransmitter release from synaptic vesicles, and secretion of a wide variety of essential hormones, digestive enzymes, and vasoactive amines. For human neutrophils (PMN), ${ }^{1}$ the fusion of lysosomes with the plasma membrane subserves both microbicidal and inflammatory functional responses. The non-oxygen-dependent killing of ingested bacteria depends on exposure of microorganisms to the toxic environment resulting from fusion of lysosomes with the organism containing phagosome. Recent evidence also suggests that oxygen-dependent microbicidal mechanisms may be partly dependent on lysosomeplasma membrane fusion because cytochrome $b$ appears to participate in the postphagocytic "respiratory burst" and this cytochrome is largely localized in the specific granules of PMN $(1,2)$. The extracellular release of PMN lysosomal constituents also contributes to evolution of the acute inflammatory response. In a process that closely resembles secretion from other cells, lysosomal enzymes can be released from PMN that generate inflammatory mediators and that have proteolytic activity against extracellular substrates.

Numerous studies have addressed the regulatory mechanisms of lysosome-plasma membrane fusion in PMN. These investigations have been largely focused on events at the plasma membrane and within the cytosol. Particular attention has been directed to the movements of extracellular and membrane-bound cations and anions (3-5), the relation of these ionic fluxes to membrane potential and surface charge changes $(6-8)$, the activation of nucleotide cyclases $(9-11)$, and the assembly and disassembly of microtubules and microfilaments (12-14). Since, in some respects, the

${ }^{1}$ Abbreviations used in this paper: 9AA, 9-aminoacridine; f-Met-Leu-Phe, formyl-methionine-leucine-phenylalanine; FITC-dex, fluorescein-labeled dextran; LDH, lactic dehydrogenase; $\mathrm{pH}_{\mathrm{i}}$, internal $\mathrm{pH}$; $\mathrm{PMA}$, phorbol myristate acetate; PMN, neutrophils. 
lysosome is the intracellular target organelle of PMN activation, we questioned whether the lysosome plays an active role in regulating its own fate during the fusion process.

Specifically, we have recently demonstrated that in a mixed population of human PMN lysosomes, the intralysosomal $\mathrm{pH}$ is highly acidic and this intralysosomal $\mathrm{pH}$ appears to be maintained by an active protontranslocating pump (15). Because the fusion between other biologic membranes (e.g., egg-sperm fertilization [16], platelet granule release [17]) is influenced by $\mathrm{pH}$ and $\mathrm{H}^{+}$fluxes, we have examined in these experiments whether alteration of the intralysosomal $\mathrm{pH}$ effects the secretory response of human PMN. These studies suggest that maintenance of an acidic intralysosomal $\mathrm{pH}$ is important to lysosome-plasma membrane fusion and that alkalinization of the intralysosomal $\mathrm{pH}$ inhibits neutrophil degranulation.

\section{METHODS}

Isolation of PMN. Heparinized blood $(20 \mathrm{U} / \mathrm{ml})$ was obtained from healthy adult volunteers after obtaining informed consent. Leukocytes containing 95-98\% PMN were isolated by Hypaque-Ficoll (Pharmacia Fine Chemicals, Piscataway, NJ) density gradient centrifugation followed by dextran sedimentation and osmotic lysis of residual erythrocytes (18). PMN were washed once in phosphate-buffered saline and finally suspended in Hanks' balanced salt solution (HBSS).

Determination of intralysosomal $\mathrm{pH}$ changes. Changes in intralysosomal $\mathrm{pH}$ were monitored by using the distribution of the fluorescent weak base, 9-aminoacridine (9AA, Sigma Chemical Co., St. Louis, MO), across the membrane. This indicator is concentrated within compartments that are acid relative to the media with consequent quenching of fluorescence (19). A stock solution of 9AA was made up at $10 \mathrm{mM}$ in ethanol and stored at $4^{\circ} \mathrm{C}$. For $\mathrm{pH}$ monitoring, this was diluted to $0.05 \mu \mathrm{M}$ in HBSS (final concentration of ethanol $0.0005 \%$ ). All aqueous solutions were adjusted to $\mathrm{pH} 7.4$ except where otherwise indicated.

Fluorescence was measured in a Perkin-Elmer 650-10S spectrophotofluorometer (Perkin-Elmer Corp., Norwalk, CT). The excitation wavelength was $400 \mathrm{~nm}$ and the emission wavelength $456 \mathrm{~nm}$, with slit widths of $5 \mathrm{~nm}$. The cuvette compartment was maintained at $37^{\circ} \mathrm{C}$ by using a circulating water bath (PolyScience Corp., Niles, IL). Buffer $(3 \mathrm{ml})$ containing $0.05 \mu \mathrm{M} 9 \mathrm{AA}$ was placed in the spectrophotofluorometer cuvette and initial fluorescence was recorded. PMN $\left(1-5 \times 10^{6} / \mathrm{ml}\right)$ were added and the suspension was thoroughly mixed; fluorescence was followed continuously until a steady state was reached. All fluorescence readings were corrected for the effect of the volumes added (1-4\%) as well as for the effect of added agents on background 9AA fluorescence.

Characteristics of 9AA fluorescence. The concentration dependence of 9AA fluorescence in HBSS (pH 7.4) was examined. Solutions of HBSS containing 9AA $(0.01-0.06 \mu \mathrm{M})$ were prepared by appropriate dilutions from the stock solution of 9AA and the fluorescence intensity was measured as described above. The effect of $\mathrm{pH}$ changes on the fluorescence of a given concentration of 9AA $(0.05 \mu \mathrm{M})$ in HBSS was also examined. Solutions of HBSS containing $0.05 \mu \mathrm{M}$ 9AA were adjusted to $\mathrm{pH} 5.0-8.0$ with concentrated $\mathrm{NaOH}$ or $\mathrm{HCl}$ and the fluorescence intensity was measured. Similarly, the effects of external $\mathrm{pH}$ changes on the quenching of 9AA fluorescence in the presence of PMN $\left(4 \times 10^{6} / \mathrm{ml}\right)$ was determined over the $\mathrm{pH}$ range 5.2-7.5.

The intracellular locale of 9AA was investigated by using a digitonin-lysis method which differentially disrupts plasma membranes and lysosomes $(20-21)$. PMN $\left(5 \times 10^{6} / \mathrm{ml}\right.$ in HBSS) were incubated with varying concentrations of digitonin (Sigma Chemical Co.) for $30 \mathrm{~s} \mathrm{at} 37^{\circ} \mathrm{C}$; this was followed by centrifugation at $12,000 \mathrm{~g}$ for $1 \mathrm{~min}$. Supernatants were assayed for the cytosolic enzyme, lactate dehydrogenase, and the lysosomal enzyme, lysozyme, as described below. In parallel experiments, PMN $\left(4 \times 10^{6} / \mathrm{ml}\right)$ were incubated with 9AA $(0.05 \mu \mathrm{M})$ and fluorescence was monitored continuously until a steady state was reached. Varying concentrations of digitonin were then added and the changes in $9 \mathrm{AA}$ fluorescence determined. The effects of digitonin on 9AA fluorescence in the absence of PMN was also determined in control solutions and fluorescence determinations were corrected for these effects.

Effects of weak bases on 9AA fluorescence. To determine the effects of permeant weak bases on the distribution and fluorescence of $9 \mathrm{AA}$ in the presence of PMN, fluorescence of 9AA was measured before and after the addition of PMN. After steady state was reached, various weak bases were added and the quenching of 9AA fluorescence was continuously monitored. The weak base additions included methylamine $(1.0 \mathrm{mM})$, chloroquine $(0.1-1.0 \mathrm{mM})$, clindamycin $(1.0 \mathrm{mM})$, propanolol $(1.0 \mathrm{mM})$, and ammonium chloride $(0.1-50.0 \mathrm{mM})$. The $\mathrm{pH}$ of all added solutions was preadjusted to produce an external $\mathrm{pH}$ change of no greater than $0.1 \mathrm{pH}$ units at their final dilutions with PMN and 9AA.

Incubation of PMN with degranulating stimuli and weak bases. PMN were suspended in HBSS at a final density of $2 \times 10^{7} / \mathrm{ml}$. Aliquots of $0.5 \mathrm{ml}$ of the cell suspension were mixed with $0.5 \mathrm{ml}$ of HBSS or with $0.5 \mathrm{ml}$ of HBSS containing the degranulating stimuli, ionophore A23187 $\left(5 \times 10^{-7} \mathrm{M}\right)$; phorbol myristate acetate (PMA, $1 \mathrm{ng} / \mathrm{ml}$ ); or the synthetic chemotactic peptide, formyl-methionine-leucine-phenylalanine (f-Met-Leu-Phe, $10^{-8} \mathrm{M}$ ) plus cytochalasin B (5 $\mu \mathrm{g} /$ $\mathrm{ml}$ ). All solutions were carefully adjusted to $\mathrm{pH}$ 7.2. After a 20 -min incubation at $37^{\circ} \mathrm{C}$ in a shaking water bath, the cell suspensions were centrifuged; the cell-free supernates were saved for enzyme determinations. An aliquot of the cell suspension was also retained for freeze-thawing (four times) to determine total cellular enzyme contents.

The effects of various weak bases on degranulation in response to the ionophore A23187, PMA, and f-Met-Leu-Phe plus cytochalasin B were also examined. PMN (final density $1 \times 10^{7} / \mathrm{ml}$ ) were preincubated for $10 \mathrm{~min}$ at $37^{\circ} \mathrm{C}$ in HBSS or HBSS supplemented with the following bases: ammonium chloride, methylamine, chloroquine, ethylamine, propylamine, propanolol, clindamycin, and dansylcadaverine. All solutions were adjusted to $\mathrm{pH}$ 7.2. Buffer or the degranulating stimuli were then added at the concentrations indicated above and the incubation was continued for $20 \mathrm{~min}$ at $37^{\circ} \mathrm{C}$ in a shaking water bath. The cell-free supernatants were then obtained by centrifugation and used for enzyme determinations. Each condition was run in duplicate.

To determine whether the effects of weak bases on PMN uptake of 9AA and secretion were reversible, PMN $\left(1 \times 10^{7}\right)$ $\mathrm{ml}$ ) were incubated in HBSS ( $\mathrm{pH}$ 7.2) or HBSS supplemented with ammonium chloride $(10 \mathrm{mM}, \mathrm{pH} 7.2)$ for $5 \mathrm{~min}$ at $37^{\circ} \mathrm{C}$ in some experiments. The cell suspensions were then centrifuged $\left(400 \mathrm{~g}\right.$ for $5 \mathrm{~min}$ at $\left.4^{\circ} \mathrm{C}\right)$ and resuspended in HBSS or HBSS containing A23187 $\left(5 \times 10^{-7} \mathrm{M}\right)$. The quenching 
of 9AA fluorescence and enzyme release in response to A23187 by PMN that was preincubated in HBSS or HBSS with ammonium chloride were compared as described above.

Enzyme determinations. Degranulation was monitored by the extracellular release of the lysosomal enzymes, lysozyme and $\beta$-glucuronidase. The cytosolic enzyme, lactic dehydrogenase, was also measured to determine whether enzyme release was the result of cell death.

Lysozyme activity was determined by measuring the rate of lysis of Micrococcus lysodeikticus (Worthington Biochemical Corp., Freehold, NJ) at pH 6.2 according to a turbidimetric method (22). $\beta$-glucuronidase was assayed by measuring the release of phenolphthalein from its $\beta$-glucuronate (Sigma Chemical Co.) after $4 \mathrm{~h}$ of incubation at $\mathrm{pH}$ 4.5 (23). Lactic dehydrogenase ( $\mathrm{LDH}$ ) was assayed by spectrophotometric measurement of the consumption of $\beta$-nicotinamide adenine dinucleotide during the conversion of pyruvate to lactate (24). Enzyme activities are expressed as a percent of total enzyme activity in a sample of PMN ( 1 $\times 10^{7} / \mathrm{ml}$ ) in the various media freeze-thawed four times. None of the weak bases affected the activities of lysozyme, $\beta$-glucuronidase, or lactic dehydrogenase.

\section{RESULTS}

Monitoring intralysosomal pH with 9AA fluorescence. To use 9AA fluorescence as a weakly basic probe to monitor $\mathrm{pH}$ changes within PMN lysosomes, several prerequisites must be fulfilled. First, the fluorescence of $9 \mathrm{AA}$ must be concentration-dependent so that its accumulation in acidic compartments will result in concentration changes that can be detected by changes in the intensity of fluorescence. As shown in Fig. 1, 9AA fluorescence was highly concentration-dependent over the range $0.01-0.06 \mu \mathrm{M}$. For subsequent studies with PMN, the concentration of $9 \mathrm{AA}$ incubated with the cells was $0.05 \mu \mathrm{M}$. Second, the fluorescence of the probe itself must be $\mathrm{pH}$-independent. As shown in Fig. 2, the absolute fluorescence of 9AA $(0.05 \mu \mathrm{M})$ was completely unaffected by suspension in HBSS preadjusted to $\mathrm{pH}$ that vary from 5 to 8 . Third, if the

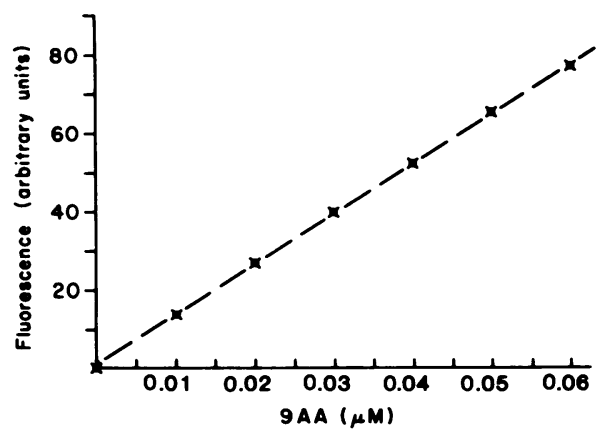

Figure 1 Concentration dependence of 9AA fluorescence. Solutions of 9AA were made in HBSS ( $\mathrm{pH} \mathrm{7.2).} \mathrm{Fluorescence}$ was measured with excitation at $400 \mathrm{~nm}$ and emission at $456 \mathrm{~nm}$.

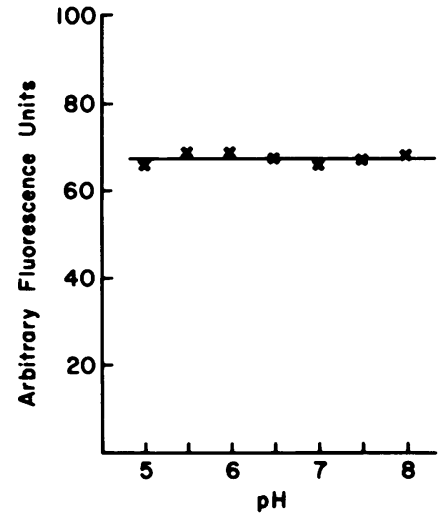

Figure $2 \mathrm{pH}$ independence of 9AA fluorescence. Solutions of 9AA $(0.05 \mu \mathrm{M})$ were made in HBSS and adjusted to $\mathrm{pH}$ $5-8$. Fluorescence was measured as in Fig. 1.

accumulation of 9AA in lysosomes is dependent on a $\Delta \mathrm{pH}$ (i.e., 9AA behaves as a weak base), then changing the extracellular $\mathrm{pH}$ should affect the lysosomal uptake of 9AA and thereby, modify the fluorescent signal. When the gradient between extracellular $\mathrm{pH}$ and the intralysosomal $\mathrm{pH}$ is minimal (e.g., at acidic extracellular $\mathrm{pH}$ ), small quantities of 9AA should accumulate within the lysosomes and the fluorescence should not be quenched. Conversely, at neutral or alkaline extracellular $\mathrm{pH}, 9 \mathrm{AA}$ should concentrate within the lysosomes and increase the quenching of 9AA fluorescence. Fig. 3 shows the relationship between modifying the extracellular $\mathrm{pH}$ and the quenching of 9AA fluorescence in the presence of intact PMN. In accordance with the predictions that 9AA behaves as a weak base, there was a progressive increase in the quenching of 9AA fluorescence as the extracellular $\mathrm{pH}$ was raised from 5.2 to 7.5. Finally, to use 9AA as a probe of intralysosomal

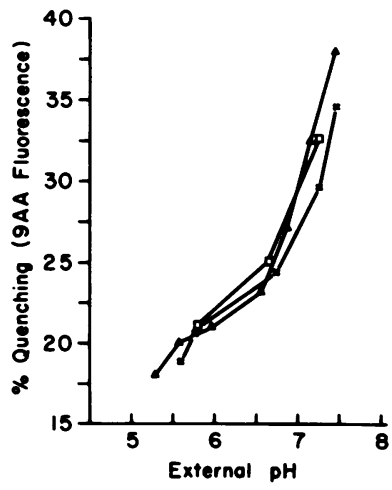

Figure 3 Effect of external $\mathrm{pH}$ on 9AA fluorescence with intact PMN. PMN $\left(4 \times 10^{6} / \mathrm{ml}\right)$ were incubated with 9AA $(0.05 \mu \mathrm{M})$ in HBSS adjusted to various $\mathrm{pH}$ and the quenching of 9AA fluorescence was measured. Results from three separate experiments are shown. 
$\mathrm{pH}$, it is necessary to verify that $9 \mathrm{AA}$ is largely localized within this intracellular compartment. Our approach has been to examine the correlation between release of a cytoplasmic marker (LDH), which is indicative of plasma membrane disruption, and release of a lysosomal marker (lysozyme), which is indicative of lysosomal membrane disruption with release of 9AA induced by the detergent digitonin. As shown in Table I, LDH release was dependent on the concentration of digitonin and was maximal at $0.025 \mathrm{mM}$. While lysozyme release by digitonin was also concentration-dependent, maximal lysosomal disruption did not occur until $0.1 \mathrm{mM}$. Digitonin-induced release of 9AA (as assessed by reversal of fluorescence quenching) showed a remarkable correlation with the lysozyme release. Whereas 0.025 $\mathrm{mM}$ digitonin resulted in maximal $\mathrm{LDH}$ release, only $33.8 \%$ of lysozyme and $15.4 \%$ of $9 \mathrm{AA}$ was released at this concentration. A higher digitonin concentration $(0.10 \mathrm{mM})$ was required to induce maximal release of lysozyme and 9AA.

The ability of various weak bases to raise the intralysosomal $\mathrm{pH}$ as monitored by reversal of the quenching of 9AA fluorescence is shown in Fig. 4. At the concentrations shown, each of the weak bases reversed the PMN quenching of 9AA fluorescence. This results from redistribution of the $9 \mathrm{AA}$ out of the lysosome as the weak bases increase the intralysosomal $\mathrm{pH}$ and thereby, reduce the transmembrane $\mathrm{pH}$ gradient. As would be predicted from this model, reversal of fluorescence quenching of $9 \mathrm{AA}$ by the weak bases was dose-dependent. As shown in Fig. 5, increasing concentrations of ammonium chloride progressively reversed the quenching of $9 \mathrm{AA}$ fluorescence.

Effects of weak bases on degranulation. In the absence of a secretory stimulus, spontaneous release of LDH and lysozyme was similar for PMN incubated in HBSS or HBSS containing the various weak bases ( $<4.0 \%$, data not shown). Figs. 6-8 demonstrate the effects of various weak bases on secretion of lysozyme

TABLE I

Release of Indicators from PMN By Digitonin Lysis

\begin{tabular}{lcccc}
\hline & \multicolumn{5}{c}{ Digitonin (mM) } \\
\cline { 2 - 5 } & 0 & 0.001 & 0.025 & 0.10 \\
\hline Lactate & & & & \\
$\quad$ dehydrogenase & $11.1 \pm 1.8^{\circ}$ & $7.6 \pm 0.8$ & $79.9 \pm 6.2$ & $83.7 \pm 4.6$ \\
Lysozyme & $8.3 \pm 1.1$ & $8.8 \pm 1.0$ & $33.8 \pm 2.7$ & $84.7 \pm 0.7$ \\
9AA & $5.8 \pm 3.8$ & 0 & $15.4 \pm 0.4$ & $81.3 \pm 4.4$ \\
\hline
\end{tabular}

- Release of indicators is expressed as a mean \pm SEM of the percentage of maximal release obtained by treating PMN with $0.02 \%$ Triton X-100 in two to seven experiments that were each run in duplicate.

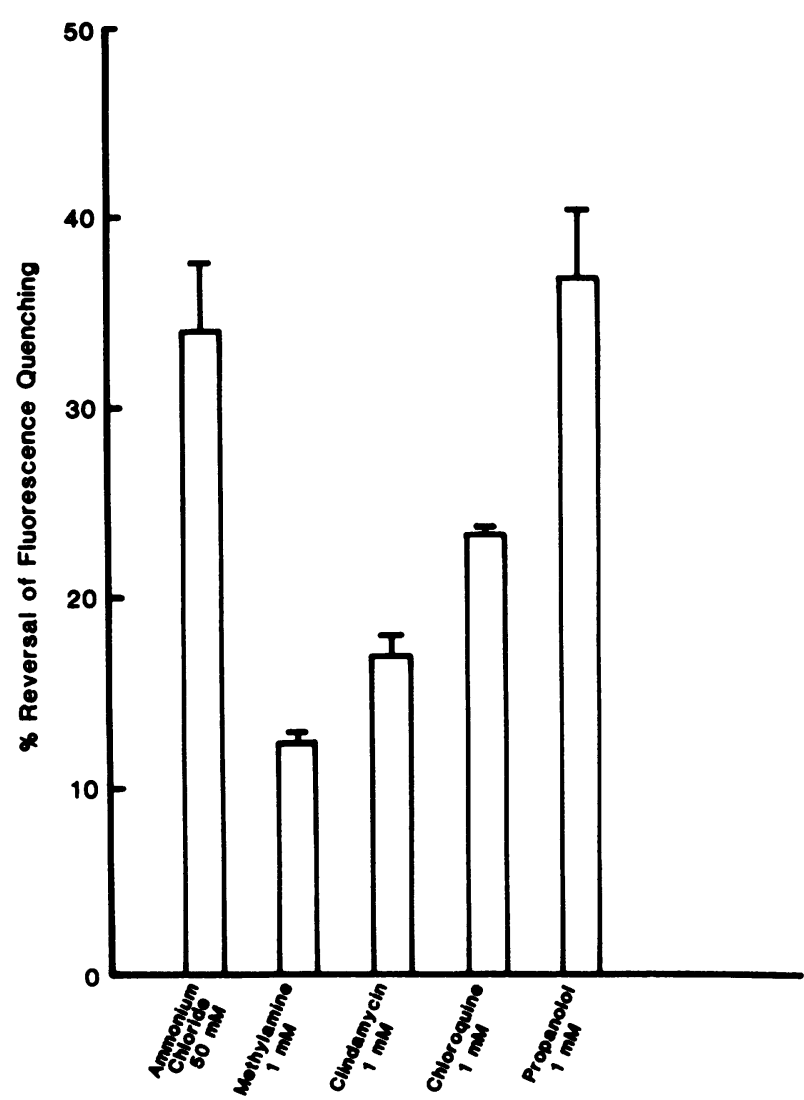

Figure 4 Effect of weak bases on intralysosomal pH. PMN were equilibrated with $9 \mathrm{AA}(0.05 \mu \mathrm{M})$ and quenching of 9AA fluorescence was measured (excitation $400 \mathrm{~nm}$, emission $456 \mathrm{~nm}$ ). Each of the bases was then added and reversal of fluorescence quenching was determined. None of the bases increased 9AA fluorescence in the absence of PMN.

by $\mathrm{PMN}$ in response to the $\mathrm{Ca}^{++}$ionophore $\mathrm{A} 23187$ (Fig. 6), PMA (Fig. 7), and f-Met-Leu-Phe plus cytochalasin B (Fig. 8). Under control conditions, which were without any weak base present, these secretory stimuli induced lysozyme release between 24.2 and $38.0 \%$ of total cellular lysozyme. All supernates contained $<4 \%$ of the cytosolic enzyme, lactate dehydrogenase; this indicates that lysozyme release was not due to cell death. In the absence of a weak base, $\beta$ glucuronidase release was $33.9 \pm 1.1,8.0 \pm 0.8$, and $15.7 \pm 0.5 \%$ of total cellular enzyme for cell suspensions treated with A23187, PMA, and f-Met-Leu-Phe plus cytochalasin B, respectively (not shown). At the concentrations shown, each of the weak bases inhibited lysozyme release in response to the secretory stimuli. The most profound inhibitory effect was consistently seen with the weakly basic antibiotic, clindamycin. At a clindamycin concentration of $10^{-3} \mathrm{M}$, there was a 92.2 and $91.5 \%$ inhibition of lysozyme release in re- 


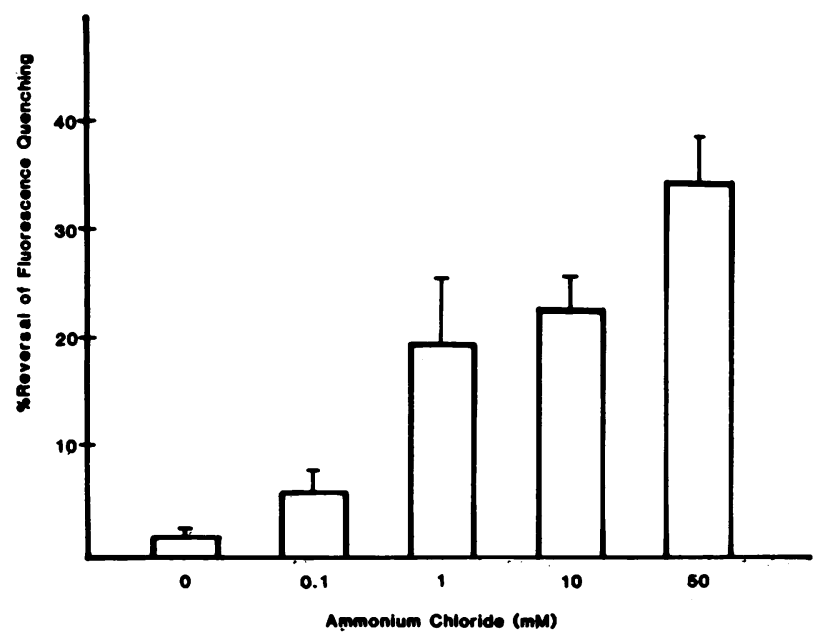

Figure 5 Alkalinization of intralysosomal $\mathrm{pH}$ by ammonium chloride. PMN $\left(5 \times 10^{6} / \mathrm{ml}\right)$ were incubated with 9AA $(0.05$ $\mu \mathrm{M})$ and the reversal of 9AA fluorescence quenching by increasing concentrations of ammonium chloride was measured as in Fig. 4. Volume additions were constant for each concentration of ammonium chloride ( $1 \%$ of total volume) and reversal of fluorescence quenching was corrected for this dilution effect.

sponse to A23187 and PMA, respectively, and at $10^{-4} \mathrm{M}$, lysozyme release in response to the chemotactic peptide was inhibited by $76.4 \%$. $\beta$-glucuronidase release in response to A23187 and the chemotactic peptide was also consistently inhibited by the weak bases at the same concentrations (not shown). Although PMA-induced $\beta$ -

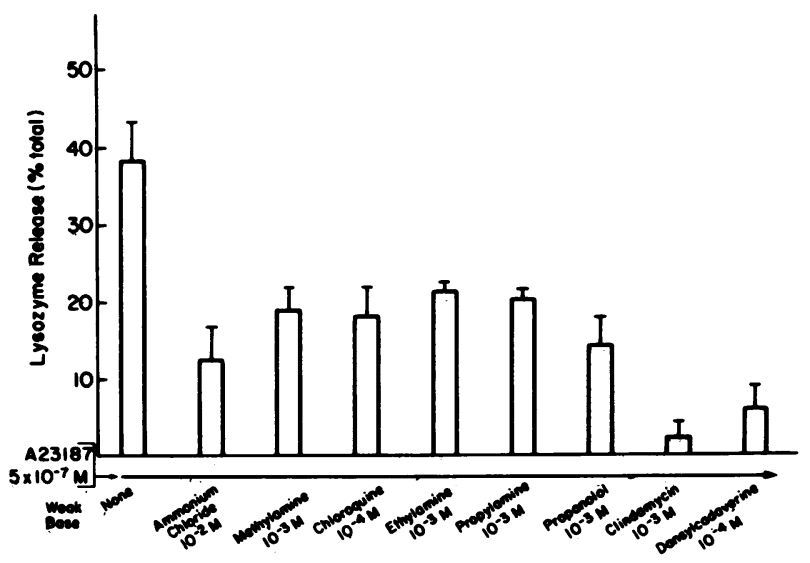

Figure 6 Effects of weak bases on lysozyme release by PMN stimulated with A23187. PMN $\left(1 \times 10^{7} / \mathrm{ml}\right)$ were preincubated with HBSS or HBSS supplemented with the weak bases at the concentrations indicated $\left(\mathrm{pH} \mathrm{7.2)}\right.$ for $10 \mathrm{~min}$ at $37^{\circ} \mathrm{C}$. Lysozyme release in cell-free supernates was measured after stimulation with $\mathrm{A} 23187\left(5 \times 10^{-7} \mathrm{M}\right)$ for $20 \mathrm{~min}$ at $37^{\circ} \mathrm{C}$. LDH release was $<4 \%$ in all supernates. Results are the mean $\pm S E M$ of four separate experiments.

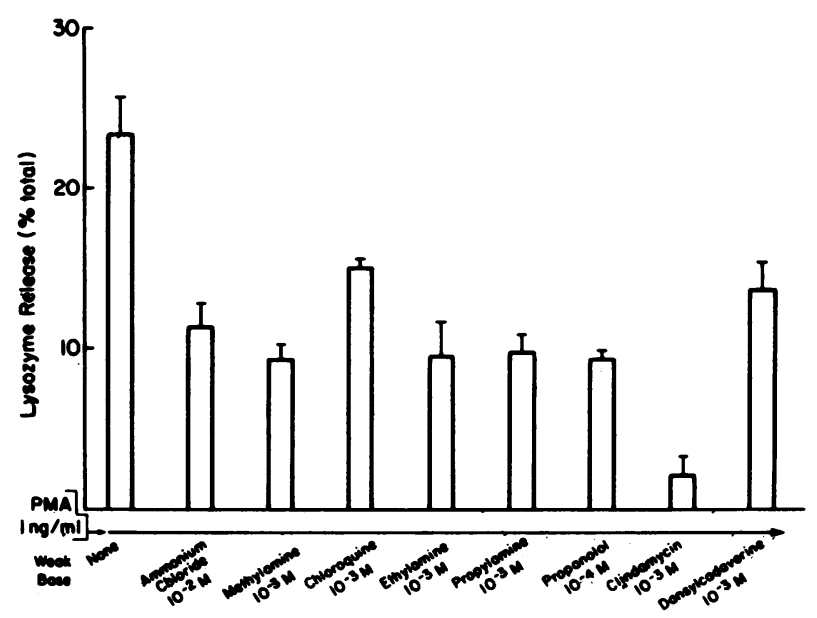

Figure 7 Effects of weak bases on lysozyme release by PMN stimulated with phorbol myristate acetate. Conditions were as in Fig. 6 with the secretory stimulus, phorbol myristate acetate $(1 \mathrm{ng} / \mathrm{ml})$. Results are the mean \pm SEM of three separate experiments.

glucuronidase release was $<10 \%$ in the absence of a weak base, this small degree of enzyme release was further inhibited by clindamycin $(1 \mathrm{mM})$, methylamine (1 $\mathrm{mM})$, propanolol (1 $\mathrm{mM})$, and chloroquine $(0.1 \mathrm{mM})$ (data not shown).

The dose-response relationship between increasing concentrations of ammonium chloride and A23187stimulated lysozyme release is shown in Fig. 9. In the absence of any weak base, A23187 stimulated $47.3 \pm 2.9 \%$ of total cellular lysozyme release. Ammonium chloride at 0.1 and $0.5 \mathrm{mM}$ did not inhibit

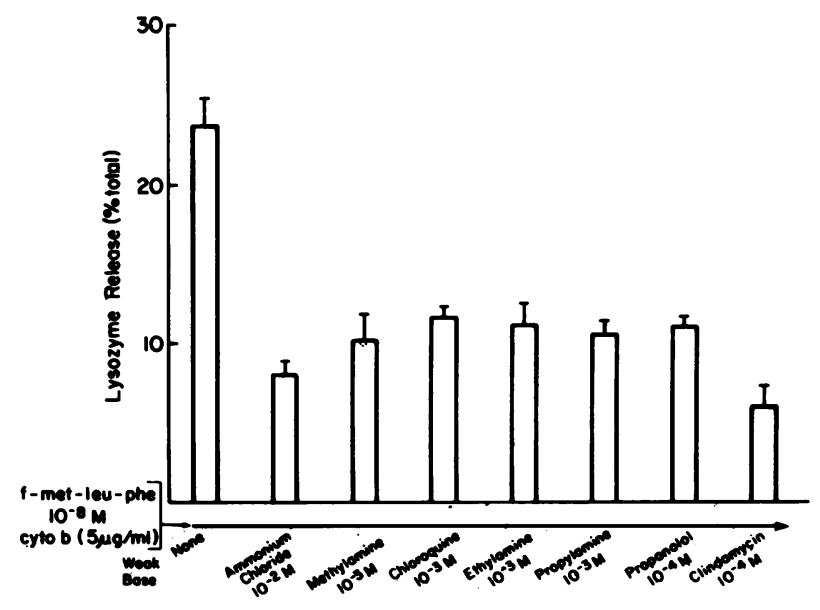

Figure 8 Effects of weak bases on lysozyme release by PMN stimulated with $\mathrm{f}$-Met-Leu-Phe $\left(10^{-8} \mathrm{M}\right)$ plus cytochalasin B $(5 \mu \mathrm{g} / \mathrm{ml})$. Conditions were as in Fig. 6. Results are the mean $\pm S E M$ of three separate experiments. 


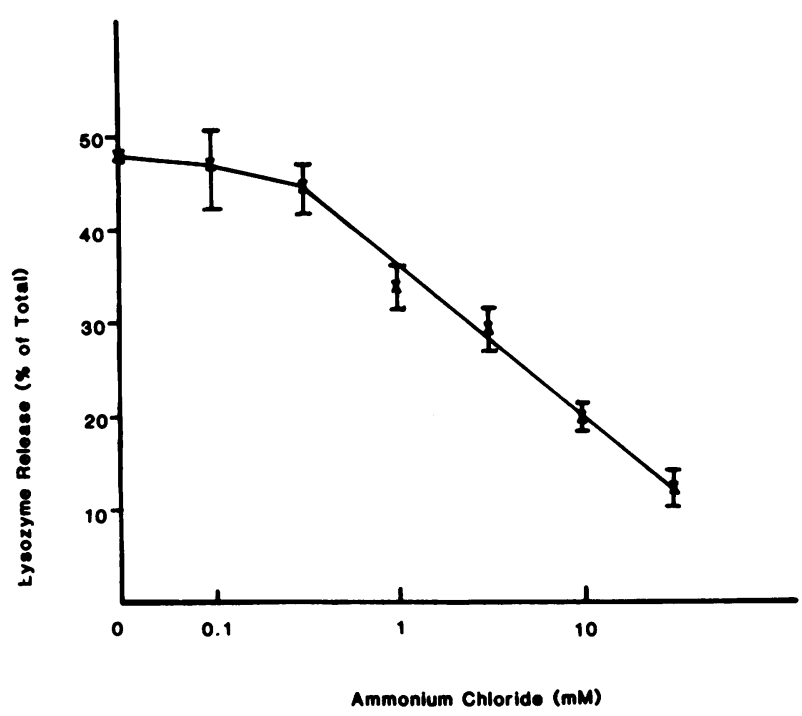

Figure 9 Dose response of ammonium chloride inhibition of lysozyme release by PMN stimulated with A23187 $\left(5 \times 10^{-7} \mathrm{M}\right)$. Conditions were as in Fig. 6 with PMN preincubated with HBSS or HBSS supplemented with increasing concentrations of ammonium chloride. Results are the mean $\pm S E M$ of three separate experiments.

A23187-stimulated lysozyme release. At higher ammonium chloride concentrations, however, there was progressive inhibition of degranulation by this weak base.

The effects of ammonium chloride on PMN quenching of 9AA fluorescence and secretion in response to A23187 were reversible. Quenching of 9AA fluorescence by control, HBSS-treated cells was $36.5 \pm 3.9 \%$, and was $37.9 \pm 4.5 \%$ after PMN had been preincubated in ammonium chloride $(10 \mathrm{mM})$ for $5 \mathrm{~min}$ and then resuspended in ammonium chloride-free HBSS $(\mathrm{pH}$ $7.2, n=3, P>0.1$ ). After ammonium chloride pretreatment and removal of the weak base, PMN released $32.9 \pm 1.9 \%$ of total cellular lysozyme in response to $\mathrm{A} 23187\left(20 \mathrm{~min}\right.$ at $\left.37^{\circ} \mathrm{C}\right)$ and control PMN released $25.9 \pm 2.4 \%$. Spontaneous lysozyme release (in the absence of A23187) was $3.9 \pm 1.7 \%$ for ammonium chloride-treated cells and $4.1 \pm 1.6 \%$ for control cells. These results are the mean \pm SEM of four separate experiments that were each run in triplicate.

\section{DISCUSSION}

In a previous study, we demonstrated that the $\mathrm{pH}$ within a mixed population of isolated human PMN lysosomes was highly acidic and proposed that this preformed acid was a principal source of protons for the acidification of the phagocytic vacuole after phagosome-lysosome fusion (15). That the intralysosomal $\mathrm{pH}$ was only partially alkalinized by the protonophore, carbonyl cyanide $m$-chlorophenyl hydrazone, and that the $\Delta \mathrm{pH}$ was almost completely abolished by the combination of carbonyl cyanide $m$-chlorophenyl hydrazone with the $\mathrm{K}^{+}$ionophore, valinomycin, suggested the existence of an electrogenic $\mathrm{H}^{+}$pump for maintenance of the intralysosomal acid $\mathrm{pH}$. In these studies, we utilized a method for monitoring the intralysosomal $\mathrm{pH}$ in intact PMN based on the accumulation of a weakly basic fluorescent probe, 9AA, within these acidic lysosomes. Using this method, we have investigated whether permeant weak bases, which accumulate within intracellular acidic lysosomes and alkalinize the intralysosomal $\mathrm{pH}$, have an effect on the availability of lysosomal contents for extracellular release in response to several stimuli. Our studies demonstrate that alkalinization of the intralysosomal $\mathrm{pH}$ by weak base accumulation markedly inhibited PMN degranulation in response to A23187, PMA, or f-Met-Leu-Phe plus cytochalasin B.

The use of $9 \mathrm{AA}$ as a weak base fluorescent probe was first introduced by Deamer et al. (19) for the measurement of intraliposomal $\mathrm{pH}$ and has subsequently been used to measure the $\mathrm{pH}$ in several systems, including mitochondria (25), secretory granules (26), sperm cells (27), and platelets (17). Like other weak bases, 9AA accumulates in acidic compartments down a $\mathrm{pH}$ gradient and demonstrates a concentration-dependent quenching of fluorescence. Quenching is thought to result from self-interactions between 9AA molecules as a function of $9 \mathrm{AA}$ concentration (19). Thus, the fluorescence of $9 \mathrm{AA}$ is proportional to its concentration and it concentrates in acidic compartments, including PMN lysosomes. As emphasized by Simons et al. (17), 9AA fluorescence changes are proportional to internal $\mathrm{pH}\left(\mathrm{pH}_{\mathrm{i}}\right)$ changes, but do not provide a priori an accurate measure of absolute $\mathrm{pH}_{\mathrm{i}}$; we utilized this probe to monitor changes in intralysosomal $\mathrm{pH}$.

The major requirements for using 9AA fluorescence as a probe of intralysosomal $\mathrm{pH}$ are that $(a)$ the intensity of fluorescence be a measure of 9AA concentration in our buffer system, $(b)$ that the fluorescence of a given concentration of $9 \mathrm{AA}$ be $\mathrm{pH}$-independent over the $\mathrm{pH}$ range of interest, and $(c)$ that the probe localizes predominantly in the lysosome. Figs. 1 and 2 verify the applicability of 9AA fluorescence as a concentrationdependent, $\mathrm{pH}$-independent parameter in our system. Several observations serve to justify the interpretation of changes in 9AA fluorescence as a reflection of changes in lysosomal $\mathrm{pH}_{\mathrm{i}}$. The intracellular compartments of PMN include cytosol, nucleus, lysosomes, mitochondria, and endoplasmic reticulum. Of these, only lysosomes have been demonstrated to have an acidic $\mathrm{pH}_{\mathrm{i}}$ that would lead to 9AA accumulation (15). Since the $\mathrm{pH}_{\mathrm{i}}$ of mitochondria is alkaline in other cells (27), it is highly unlikely that 9AA would accumulate in this 
compartment. There should also be little, if any, 9AA accumulation in the cytoplasm since the $\Delta \mathrm{pH}$ between the cytoplasm and media (at neutral $\mathrm{pH}$ ) has been measured at $<0.01 \mathrm{pH} \mathrm{U}(28)$. Moreover, stimulation of PMN with, for example, f-Met-Leu-Phe leads to alkalinization of cytoplasmic $\mathrm{pH}$, which would tend to exclude 9AA. To our knowledge, the intranuclear $\mathrm{pH}$ of PMN has not been directly measured. However, the high concentrations of basic histones in PMN nuclei (29) suggests that 9AA would not concentrate in this organelle. A recent report by Smolen et al. (30) also supports the lysosome as the site of 9AA accumulation in PMN. These studies demonstrated a high correlation between the extracellular release of 9AA from PMN loaded with this dye in a preliminary incubation and the release of lysosomal enzymes in response to several secretory stimuli. Our direct studies also indicate that the lysosome is, in large part, the intracellular site of 9AA uptake. We have patterned these experiments after those of Zuurendonk and Tager (20) and Akkermann et al. (21) who demonstrated differential digitonin lysis of plasma membranes and intracellular organellar membranes in rat hepatocytes and human platelets, respectively. At digitonin concentrations which maximally liberated a cytoplasmic enzyme, LDH, there was relative preservation of lysozyme and 9AA within a sequestered compartment. Although this is not direct proof that 9AA is in lysosomes, when it is taken together with the considerations above, it provides strong support that $9 \mathrm{AA}$ is a useful probe for studies of lysosomal $\mathrm{pH}_{\mathrm{i}}$.

Our finding that a variety of weak bases alkalinized the intralysosomal $\mathrm{pH}$ in $\mathrm{PMN}$ is similar to the observations of Poole and Ohkuma (31) on mouse peritoneal macrophages. These investigators used fluorescein-labeled dextran (FITC-dex), which accumulated by endocytosis in macrophage phagolysosomes over $24 \mathrm{~h}$, as a $\mathrm{pH}$-dependent probe to measure the effects of weak bases on intralysosomal $\mathrm{pH}$. Their results demonstrated a dose-dependent alkalinization of lysosomal $\mathrm{pH}_{\mathrm{i}}$ by chloroquine and several simple amines. The concentrations required for raising the macrophage phagolysosomal $\mathrm{pH}_{\mathrm{i}}$ were comparable with those used in our studies, and alkalinization of the phagolysosomal $\mathrm{pH}_{\mathrm{i}}$ by ammonium chloride was rapidly reversible once the weak base was removed from the media. It should, however, be emphasized that the FITC-dex method requires endocytosis of the probe; this could alter the composition of the compartment that contains the FITC-dex. Indeed, recent evidence demonstrates that clathrin-coated endocytic vesicles contain an ATP-dependent proton pump that acidifies the intravesicular space and may be the site of at least some of the FITCdex localization (32). In contrast, our studies with the permeant weak base probe 9AA presumably do not involve endocytosis of the probe, but rather passage of the uncharged base across the plasma membrane and lysosomal membrane where it accumulates because of the already existent $\Delta \mathrm{pH}$.

The highly consistent findings that weak bases not only alkalinize the intralysosomal $\mathrm{pH}$, but inhibit granule release in response to several secretory stimuli is not surprising when considered in the context of other systems requiring membrane fusion. This is perhaps best exemplified by the studies of Helenius et al. (33) on the pathway of viral genome entry into the cytoplasm of host cells. For example, Semliki forest virus and canine influenza virus are endocytosed into vesicles where an acidic $\mathrm{pH}$ is required for the viral membrane fusion reaction that results in transfer of the viral genome into the cytoplasm (34). Ammonium chloride, which alkalinizes this vesicular compartment, inhibits the fusion reaction and infectivity of the virus for the host cell. An acid $\mathrm{pH}$ also appears to be important for the intravesicular processing (dissociation) of receptor-ligand complexes and the recycling of the endocytosed receptor to the surface membrane (35).

That alkalinizing the intralysosomal $\mathrm{pH}$ inhibits PMN degranulation raises several questions as to the mechanisms of secretion and to the nature of the $\mathrm{pH}$ sensitive process. Current concepts of lysosomal exocytosis relegate a passive role to the lysosome in the secretory response. Rather, the regulatory controls are considered to be exclusively localized to the plasma membrane, where stimulus reception and transduction occur, and in the cytosol, where alterations in the chemical environment (e.g., ionic composition, cyclic nucleotides, products of arachidonic acid metabolism, etc.) are expressed in terms of assembly and disassembly of contractile protein matrices and tubulin. Although it is possible that the lysosome exerts its influence on the secretory process through these same mechanisms, for example, as a site of mobilizable intracellular calcium, it is also possible that an acidic intralysosomal $\mathrm{pH}$ is required for the poorly defined biochemical reactions that lead ultimately to membrane fusion. Future investigation should be directed at identifying the nature of lysosomal participation in regulating its own fate during secretion.

\section{ACKNOWLEDGMENTS}

We thank Thomas Ford and Charles Pollack for expert technical assistance and Elizabeth Lundquist for preparation of the manuscript.

This work was supported in part by National Institutes of Health grant A1-16732.

\section{REFERENCES}

1. Segal, A. W., and O. T. G. Jones. 1978. Novel cytochrome $b$ system in phagocytic vacuoles from granulocytes. $\mathrm{Na}$ ture (Lond.). 276:515-517. 
2. Borregaard, N., J. M. Heiple, E. R. Simons, and R. A. Clark. 1983. Translocation of cytochrome $b$ during stimulation of human neutrophils. Clin. Res. 31:495A. (Abstr.)

3. Showell, H. J., P. H. Naccache, R. I. Sha'afi, and E. L. Becker. 1977. The effects of extracellular $\mathrm{K}^{+}, \mathrm{Na}^{+}$and $\mathrm{Ca}^{++}$on lysosomal enzyme release from polymorphonuclear leukocytes. J. Immunol. 119:804-811.

4. Hoffstein, S. 1979. Ultrastructural demonstration of calcium loss from local regions of the plasma membrane of surface stimulated human granulocytes. J. Immunol. 123:1395-1402.

5. Korchak, H. M., B. A. Eisenstat, J. E. Smolen, L. E. Rutherford, P. O. Durham, and G. Weissmann. 1982. Stimulus response coupling in the human neutrophil. The role of anion fluxes in degranulation. J. Biol. Chem. 257:6916-6922.

6. Korchak, H. M., and G. Weissmann. 1978. Changes in membrane potential of human granulocytes antecede the metabolic responses to surface stimulation. Proc. Natl. Acad. Sci. USA. 75:3818-3822.

7. Gallin, J. I. 1980. Degranulating stimuli decrease the negative surface charge and increase the adhesiveness of human neutrophils. J. Clin. Invest. 65:298-306.

8. Weissmann, G., J. E. Smolen, and H. M. Korchak. 1980. Release of inflammatory mediators from stimulated neutrophils. N. Engl. J. Med. 303:27-34.

9. Smolen, J. E., H. M. Korchak, and G. Weissmann. 1980. Increased levels of cyclic adenosine- $3^{\prime}-5^{\prime}$-monophosphate in human polymorphonuclear leukocytes after surface stimulation. J. Clin. Invest. 65:1077-1085.

10. Ignarro, L. J., and W. J. George. 1974. Hormonal control of lysosomal enzyme release from human neutrophils: elevation of cyclic nucleotide levels by autonomic neurohormones. Proc. Natl. Acad. Sci. USA. 71:2027-2031.

11. Hatch, G. E., W. K. Nichols, and H. R. Hill. 1977. Cyclic nucleotide changes in human neutrophils induced by chemoattractants and chemotactic modulators. J. Immunol. 119:450-456.

12. Gallin, J. I., and A. S. Rosenthal. 1974. The regulatory role of divalent cations in human granulocyte chemotaxis. Evidence for an association between calcium exchanges and microtubule assembly. J. Cell Biol. 62:594609.

13. Hoffstein, S., R. Soberman, I. Goldstein, and G. Weissmann. 1976. Concanavalin $A$ induces microtubule assembly and specific granule discharge in human polymorphonuclear leukocytes. J. Cell Biol. 68:781-787.

14. Yin, H. L., J. H. Hartwig, K. Maryyama, and T. P. Stossel. 1981. $\mathrm{Ca}^{++}$control of actin filament length: effects of macrophage gelsolin on actin polymerization. J. Biol. Chem. 256:9693-9697.

15. Styrt, B., and M. S. Klempner. 1982. Internal pH of human neutrophil lysosomes. FEBS (Fed. Eur. Biochem. Soc.) Lett. 149:113-116.

16. Webb, D. J., and R. Nuccitelli. 1982. Intracellular pH changes accompanying the activation and development in frog eggs. Comparision of $\mathrm{pH}$ microelectrodes and ${ }^{31} \mathrm{P}-\mathrm{MNR}$ measurements. In Intracellular pH: Its Measurement, Regulation and Utilization in Cellular Functions. R. Nuccitelli and D. W. Deamer, editors. Alan R. Liss, Inc., New York. 293-324.

17. Simons, E. R., D. R. Schwartz, and N. E. Norman. 1982. Stimulus response coupling in human platelets: thrombin-induced changes in $\mathrm{pH}_{\mathbf{i}}$. In Intracellular $\mathbf{p H}$ : Its Measurement, Regulation and Utilization in Cellular
Functions. R. Nuccitelli and D. W. Deamer, editors. Alan R. Liss, Inc., New York. 463-482.

18. Boyum, A. 1968. Isolation of mononuclear cells and granulocytes from human blood. Scand. J. Clin. Lab. Invest. 97(Suppl.):77-89.

19. Deamer, D. W., R. C. Prince, and A. R. Crofts. 1972. The response of fluorescent amines to $\mathrm{pH}$ gradients across liposome membranes. Biochim. Biophys. Acta. 274:323-335.

20. Zuurendonk, P. F., and J. M. Tager. 1974. Rapid separation of particulate components and soluble cytoplasm of isolated rat liver cells. Biochim. Biophys. Acta. 333:393-399.

21. Akkerman, J. W. N., R. H. M. Ebberink, J. P. M. Lips, and G. C. M. L. Christiaens. 1980. Rapid separation of cytosol and particle fraction of human platelets by digitonin induced cell damage. Br. J. Haematol. 44:291300 .

22. Litwack, G. 1955. Photometric determinations of lysozyme activity. Proc. Soc. Exp. Biol. Med. 89:401-403.

23. Talalay, P., W. H. Fishman, and C. Huggins. 1946. Chromogenic substrates. II. Phenolphthalein glucuronic acid as substrate for the assay of glucuronidase activity. J. Biol. Chem. 166:756-772.

24. Bergmeyer, H. U. 1963. Methods in Enzymatic Analysis. Academic Press, Inc., New York. 737-739.

25. Shuldiner, S., H. Rottenberg, and M. Avron. 1972. Determination of $\mathrm{pH}$ in chloroplasts. 2. Fluorescent amines as a probe for the determination of $\mathrm{pH}$ in chloroplasts. Eur. J. Biochem. 24:64-70.

26. Salama, G., R. G. Johnson, and A. Scarpa. 1980. Spectrophotometric measurements of transmembrane potential and $\mathrm{pH}$ gradients in chromaffin granules. J. Gen. Physiol. 75:109-140.

27. Mitchell, P., and J. Moyle. 1967. Acid-base titration across the membrane system of rat liver mitochondria. Biochem. J. 104:588-560.

28. Molski, T. F. P., P. H. Naccache, M. Volpi, L. M. Wolfpert, and R. I. Sha'afi. 1980. Specific modulation of the intracellular $\mathrm{pH}$ of rabbit neutrophils by chemotactic factors. Biochem. Biophys. Res. Commun. 94:508-514.

29. Smetana, K., J. Lejnar, and P. Kasik. 1973. Cytochemical studies on histones in the condensed chromatin of mature human leukocytes. Histochemie. 37:141-148.

30. Smolen, J. E., H. M. Korchak, and G. Weissmann. 1983. The kinetics of lysosomal degranulation of human neutrophils as measured by 9-aminoacridine quenching. Biochim. Biophys. Acta. 762:145-153.

31. Poole, B., and S. Ohkuma. 1981. Effect of weak bases on the intralysósomal $\mathrm{pH}$ in mouse peritoneal macrophages. J. Cell Biol. 90:665-669.

32. Forgac, M., L. Cantley, B. Wiedenmann, L. Altsteil, and D. Branton. 1983. Clathrin coated vesicles contain an ATP-dependent proton pump. Proc. Natl. Acad. Sci. USA. 80:1300-1303.

33. Helenius, A., J. Kartenbeck, K. Simons, and E. Fries. 1980. On the entry of Semliki Forest virus into BHK-21 cells. J. Cell Biol. 84:404-420.

34. Matlin, K. S., H. Reggio, A. Helenius, and K. Simons. 1981. Infectious entry pathway of influenza virus in a canine kidney cell line. J. Cell Biol. 91:601-614.

35. Van Renswoude, J., K. R. Bridges, J. B. Harford, and R. D. Klausner. 1982. Receptor-mediated endocytosis of transferrin and the uptake of Fe in K562 cells: identification of a nonlysosomal acidic compartment. Proc. Natl. Acad. Sci. USA. 79:6186-6190. 